\title{
Isolation and Screening of Dye Degrading Micro-organisms from the Effluents of Dye and Textile Industries at Surat
}

\author{
Mukund Chandra Thakur ${ }^{1, *}$, Arif Khan ${ }^{1}$, Hiren Dos hi ${ }^{2}$ \\ ${ }^{1}$ Dept. of Biotechnology, Ashok \& Rita Patel Institute of Integrated Study \& Research in Biotechnology and Allied Sciences, New Vallabh \\ Vidy anagar, 388121, Gujarat, India \\ ${ }^{2}$ Dept. of Pharmaceutical Chemistry; Ashok \& Rita Patel Institute of Integrated Study \& Research in Biotechnology and Allied Sciences, \\ New Vallabh Vidyanagar, 388121, Gujarat, India
}

\begin{abstract}
Textile dyes have been used since the Bronze Age. They also constitute a prototype $21^{\text {st }}$-century speciality chemicals market. Effluent and soil samples were collected from textile industry at Surat. The pH, temperature, BOD, COD, Nitrate and Nitrite values were co mpared with the values given by the Bureau of Indian Standards. The culture med ium was designed and standardized in the laboratory for the isolation and degradation of the dyes. Pure cultures were screened on the basis of colony morphology. Three different types of unique cultures we re selected and named as isolates S1, S2 \& S3. Out of 12 dyes used, is olate $\mathrm{S} 1$ showed degradation on the maximum number of dyes (five) in co mparison to other is olates (isolates S2 and S3). Thus, isolate S1 was used for the further studies. The isolate S1 was used for the study of the amount of dye to be degraded. For this study Red BB dye was chosen. Because, is olate S1 showed maximu m degradation on Red BB dye within less time of incubation in comparis on with other dyes. Almost all isolates showed the positive results in some of the biochemical tests. Thus most of the isolates can have the capacity to produce the enzyme tryptophanase, indole production, citrate permease (citrate as carbon and energy source), catalase enzyme, degradation of glucose oxidatively as well as fermentatively, urease, gelatinase, production of acid and gas (allow to ferment lactose and/or sucrose) and fermentation of sugar, lactose, sucrose, mannitol and glucose. Total cellu lar fatty acids profiling has been considered to be one of the important and ideal tool for identification of microorganis ms. On the bas is of fatty acid pro filing of isolate S1 the similarity index indicated as Bacillus cereus GC subgroup A (similarity index 0.825), B. thuringiensis sub sp. israelensis (similarity index 0.552 ) and for B. thuringiensis sub sp. Kurstakii (similarity index 0.511 ). The isolate $\mathrm{S} 1$ was assumed to be $B$. cereus GC subgroup A. Thus this isolates can be used to degrade harmful azo dyes utilized by the dye, textile, paper, ink industries etc.
\end{abstract}

Keywords Azo Dye, Degradation, Effluent, Fatty Acid Profiling, Bacillus Cereus

\section{Introduction}

The colored effluents discharged from textile processing and dye-manufacturing industries contain a significant amount of unreacted dyes. During dyeing processes, upto $15 \%$ of the dyestuff does not bind to the fibers and is therefore released into the environment[1]. The world annual production of the dyestuffs amounts to more than $7 \times 10^{5}$ tonnes[2]. Azo dyes, being the largest group of synthetic dyes, constitute up to $70 \%$ of all the known commercial dyes produced[3]. Textile processing wastewaters with dye contents in the range of 10-200 $\mathrm{mg}^{-1}$ are highly colored.

The chemical structure of coloured dyes are characterized

* Corresponding author:

thakurmukund@rocketmail.com (Mukund Chandra Thakur)

Published online at http://journal.sapub.org/ajee

Copyright (C) 2012 Scientific \& Academic Publishing. All Rights Reserved by highly substituted aromatic rings joined by one or more azo groups $(-\mathrm{N}=\mathrm{N}-)$. These substituted ring structures make these molecules recalc itrant and, thus, they are not degraded by conventional wastewater treatment processes[4]. These dyes are therefore released into the environment and lead to the acute toxic effects on the flora and fauna of the ecosystem. In addition to being aesthetically displeasing, the release of colored effluents in water bodies reduces the photosynthesis as it impedes penetration of light in water[5,6]. Moreover, many azo dyes and their metabolites are mutagenic and carcinogenic[7]. A review of the mutagenicity of effluents showed that textile and other dye related industries produce consistently more potent wastewaters when compared to other industrial discharges [8].

Recent studies by Rajaguru et al.[9] and Umbuzeiro et al.[10] have shown that azo dyes contribute to mutagenic activity of ground and surface waters polluted by textile 
effluents. Thus, the color removal of textile wastewater is a major environmental concern. There fore, industrial effluents, like textile wastewater containing dyes must be treated before their discharge into the environment. The dye wastewater from the textile is one of the most difficult wastewater to treat $[11,12]$. Because of their commercial importance, the impact and to xicity of dyes that are released in the environment have been extensively studied[13]. Colour can be removed from wastewater by chemical and physical methods including absorption, coagulation flocculation, oxidation and electrochemical methods. These methods are quite expensive, have operational problems [14], and generate huge quantities of sludge[15]. A mong low cost, viable alternatives, available for effluent treatment and decolourization, the biological systems are recognized, by their capacity to reduce biochemical oxygen demand (BOD) and chemical oxygen demand(COD) by conventional aerobic biodegradation. There is large variability in the quality of industrial effluents which varies with industrial processes. The effluents discharged by different industries contain a high range of physico-chemical parameters like temperature, $\mathrm{pH}$, conductivity, hardness, alkalinity, COD, TSS, nitrates, nitrites, cations $\left(\mathrm{Na}^{+}, \mathrm{K}^{+}, \mathrm{Ca}^{2+}\right.$ and $\left.\mathrm{Mg}^{2+}\right)$ and anions $\left(\mathrm{Cl}^{-}, \mathrm{CO}_{3}{ }^{2-}, \mathrm{HCO}_{3}{ }^{-}, \mathrm{SO}_{4}{ }^{2-}\right)$. These effluents from different industries also contain heavy metals and trace metals including chromium, cadmium, copper, lead, nickel, zinc, cobalt, magnesium, iron and arsenic[16].

The treatment systems based on using microorganisms capable of decolorizing/degrading these recalcitrant compounds are environment-friendly and can lead to mineralization of the target compounds. The effectiveness of these treatment systems depends upon the survival and adaptability of microorganisms during the treatment processes[2,17]. Many microorganisms belonging to different taxonomic groups of bacteria[2], fungi[18], actinomycetes [19] and algae[20] have been reported for their ability to decolorize azo dyes.

The use of pure-culture systemensures the reproduction of data and interpretation of the detailed mechanism of dye degradation. However, higher degree of biodegradation and mineralization can be expected when metabolic activities of mixed cultures within a microbial community complement each other. The advantages of mixed cultures are apparent as some microbial consortia can collectively carry out biodegradation that cannot be achieved by pure culture[21, 22]. Azo-dyes are also degraded efficiently under aerobic conditions by wood-rotting fungi (e. g. Phanerochaete chrysosporium, Trametes spp. etc.), which are in nature responsible for the degradation of lignin[23]. While fungal treatment of dye containing effluents is usually time consuming and difficult to control[24], the potential of enzymes for this purpose has clearly been demonstrated. Thus an effort has been made to isolate the bacteria capable of degrading the azo dyes present in the effluents of textile industries located at Surat.

\section{Materials and Methods}

For present study effluent from the dye and textile industries was used. The soil samples were also collected from the same site for study of the microbial flora in the adjourning area.

Nutrient media (Introduced by Robert Koch) was used with slight modification for the enrichment of the culture from the effluent and the soil samples.

\subsection{Collection of Effluent and Soil Sample}

The effluent sample was collected from GIDC, Pandesara, Surat, India. The $\mathrm{pH}$ and the temperature of the sample were (10.3 and $24^{\circ} \mathrm{C}$ respectively) measured at the time of collection. The Chemical oxygen demand (COD) was estimated by the titration of the effluent samp les and found to be $7507.20 \mathrm{mg} \mathrm{l}^{-1}$. The Biological oxygen demand (BOD) value could not be found for the effluent samples. The value for the nitrates and nitrites was found to be $1893 \mathrm{mgl}^{-1}$ and 70 $\mathrm{mg}^{-1}$ respectively. The soil samples were also collected fro $\mathrm{m}$ the near bank about 50 to $100 \mathrm{~cm}$ far from the effluent channel by digging the soil up to $5 \mathrm{~cm}$.

\subsection{Isolation of Dye Degrading Microorganism}

The effluent and combination of distilled water \& effluents $(\mathrm{v} / \mathrm{v})$ was inoculated in N-broth medium. To each of the flask containing $100 \mathrm{ml}$ of medium $10 \mathrm{~g}$ of soil sample was added and incubated at $28^{\circ} \mathrm{C}$ for 72 hours. Serial dilutions fro $10^{0}$ to $10^{-3}$ were made fro $\mathrm{m}$ the upper phase of the culture containing microorganisms for each of the medium separately. From each dilution $100 \mu 1$ was spread over the solid plate medium-1(Peptone $5 \mathrm{~g}$; Yeast extract $2.46 \mathrm{~g}$; $\mathrm{NaCl} 5 \mathrm{~g}$; Agar $20 \mathrm{~g}$ and $\mathrm{pH}$ to 7.00), medium -2 (Glucose $30 \mathrm{~g} ; \mathrm{KH}_{2} \mathrm{PO}_{4} 6 \mathrm{~g} ; \mathrm{Na}_{2} \mathrm{CO}_{3} 10 \mathrm{~g} ; \mathrm{MgSO}_{4} 7 \mathrm{H}_{2} \mathrm{O} 0.2$ $\mathrm{g}$; Yeast extract $6 \mathrm{~g}$; Agar $20 \mathrm{~g}$ and $\mathrm{pH}$ 7.00) containing appropriate and all different dyes separately using sterile glass spreader and incubated at $37^{\circ} \mathrm{C}$ for up to 100 hours. After incubation the observations for the zone of clearance/decolorization on the respective plates were made and recorded.

\subsection{Selection of Dye}

There were twelve different dyes (Purple H3R, Brilliant yellow, Yellow 105, Red BB, Blue 81, Blue 171, Blue 49, G Yellow, Orange 122, Dir Black \& Black 5, R 31) used in the present study.

\subsection{Optimization of Concentration of Dye Degradation}

Concentration of dye degraded by the mic roorganism was optimized for one dye and by isolate no.S1. The Red BB dye was taken in a concentration of $0.05 \%, 0.10 \%, 0.15 \%$, $0.20 \%, 0.25 \%, 0.30 \%, 0.35 \%, 0.40 \%, 0.45 \% \& 0.50 \%$ and the result was recorded.

\subsection{Biochemical Tests}

Biochemical tests were performed for checking the presence of particular substance or enzy me produced by the bacterial is olate. 


\subsubsection{Tests for Utilization of Carbohydrates and Organic Acids}

Tests for utilization of carbohydrates and organic acids were carried out by carbohydrate fermentation test, oxidation-fermentation test, methyl red test, voges-proskauer test and citrate utilization test as per the method described by Patel[25].

\subsubsection{Tests for Nitrogenous Compounds}

Tests for nitrogenous compounds was studied by perform ing indole production test, $\mathrm{H}_{2} \mathrm{~S}$ production test, deamination test, urea hydrolysis test, nitrate reduction test and ammonia production test as per the method described by Patel[25].

\subsubsection{Tests for Decomposition of Large Molecules}

Tests for decomposition of large molecules was done by starch hydrolysis test, gelatin hydrolysis test, casein hydrolysis test, catalase test and dehydrogenase test as per the method described by Patel[25].

\subsubsection{Triple Sugar Iron Test}

Combined test using composite media was performed using triple sugar iron agar test as per the method described by Patel[25].

\subsection{Cellular Fatty Acid Profiling Using GC}

\subsubsection{Sample Processing}

The pure culture was inoculated on to TSBA solid plate and incubated for 48 hours at $28^{\circ} \mathrm{C}$. The culture so obtained was harvested for cellular fatty acid profiling in following steps using Gas Chromatography.

\subsubsection{Harvesting}

A loop of cultured microorganism (about $40 \mathrm{mg}$ of bacterial cells, cultured on TSBA plate) was taken in $13 \mathrm{x}$ $100 \mathrm{ml}$ culture tube.

\subsubsection{Saponification}

In above harvested culture tube $1.0 \mathrm{ml}$ of Reagent 1 was added. The tube was tightly sealed with teflon lined caps, vortexed briefly and heated in a boiling water bath for 30 minutes. The tube was vigorously vortexed for $5-10$ seconds at an interval of 5 minutes of entire incubation period.

\subsubsection{Methylation}

After incubation the tube was cooled at room temperature, uncapped and $2 \mathrm{ml}$ of Reagent 2 was added. The tube was capped again and briefly vortexed. After vortexing, the tube ware heated for $10 \pm 1$ minutes at $80^{\circ} \pm 1^{\circ} \mathrm{C}$.

\subsubsection{Extraction}

After methylation $1.25 \mathrm{ml}$ of Reagent 3 was added to the cooled tube followed by recapping and gentle tumbling on a clinical rotator for about 10 minutes. The tube was uncapped and the aqueous (lower) phase was pipetted out and discarded.

\subsubsection{Base Wash}

About $3 \mathrm{ml}$ of Reagent 4 was added to the organic phase remained in the tube. The tube was recapped and tumbled for 5 minutes. Following uncapping, about $2 / 3$ of the organic phase was pipetted into a GC vial, capped and ready for analysis GC analysis.

The prepared sample was analyzed by gas chromatograph y (Model No. GC \# 6890N, Make - Agilent Technologies, Germany) at Disha Life Sciences, Ahmedabad. The GC instrument had flow rate of gases $-60 \mathrm{psi}$, capillary colu mn (length - 25 meter, ID- 0.20) made by Methylepolysilo xane (5\% phenyl), flame ionization detector, temperature slopeinitial te mp. 170 to $310^{\circ} \mathrm{C}$, auto injector $100 \mathrm{v}$ ial tray.

The RTSBA6 6.00 library method was used to found out the similarity index of the is olate on the bas is of total cellular fatty acids profiling. The table, graph and result so obtained were recorded.

\section{Results \& Discussion}

The effluents sample collected had the $\mathrm{pH}$ nearer to the permissible range. The average and permissible $\mathrm{pH}$ for the effluents of azo dye industries is 9[26]. Hence, the effluents will not have adverse impact on aquatic ecosystem after being discharged. The permissible limit of BOD is $3000 \mathrm{mg}$ $\mathrm{I}^{-1}$ and COD is $15000 \mathrm{mg}^{-1}$ as set by the Bureau of Indian Standards[27]. Wastes containing high BOD and COD are responsible for a heavy depletion of oxygen levels in the particular sector of the stream or soil[28]. The value for the nitrates $\left(1893 \mathrm{mgl}^{-1}\right)$ and nitrites $\left(70 \mathrm{mgl}^{-1}\right)$ was found to be higher than the permissible limit. The microorganisms present in the sewage reduce the nitrate into nitrite and then to ammonia, sulphates into sulphides and ferric iron into ferrous iron at very low concentrations of oxygen. Therefore, they create great nuisance for the environment[29]. The data for COD $\left(7507.20 \mathrm{mgl}^{-1}\right)$ revealed that the effluents in present condition are fit for discharge to land/ water bodies, as it would not be hazardous for human and aquatic life due to the lower concentration of toxicants.

\subsection{Isolation of Dye Degrading Microorganism}

The result of the dye degradation by the is olate is shown in figure 1(a-f). An analysis of the data reveals that out of four solid media used three did not show the degradation of dye by the growing microorganis ms. All the media used differs in the capacity to support the growth of dye degrading microorganis ms. The degradation was seen in the Red BB, purple H3R, BHE 81, Dir Black and blue 171 dye.

In rest of the 7 dyes used were not degraded by any of the isolates obtained from the enrichment cultures. Out of the above five, Red BB was found to be degraded more by the isolates. The change in color is due to the dye utilized by the 
isolates. The isolates were named on the basis of colony morphology from dye degradation and were named as S1, S2 and S3. Out of 3 isolates, one isolate (S1) showed degradation on all five dyes used. Thus $\mathrm{S} 1$ was subjected for the further study.

The growth of the culture on medium-2 could have attributed due to less concentration of glucose in the previous medium (medium-1) used. With the addition and/or substitution of the above factors the bacteria could grow on the medium plate which was conducive for the organis ms. Bacterial decolorization of azo dyes under methanogenic conditions is non-specific [30].
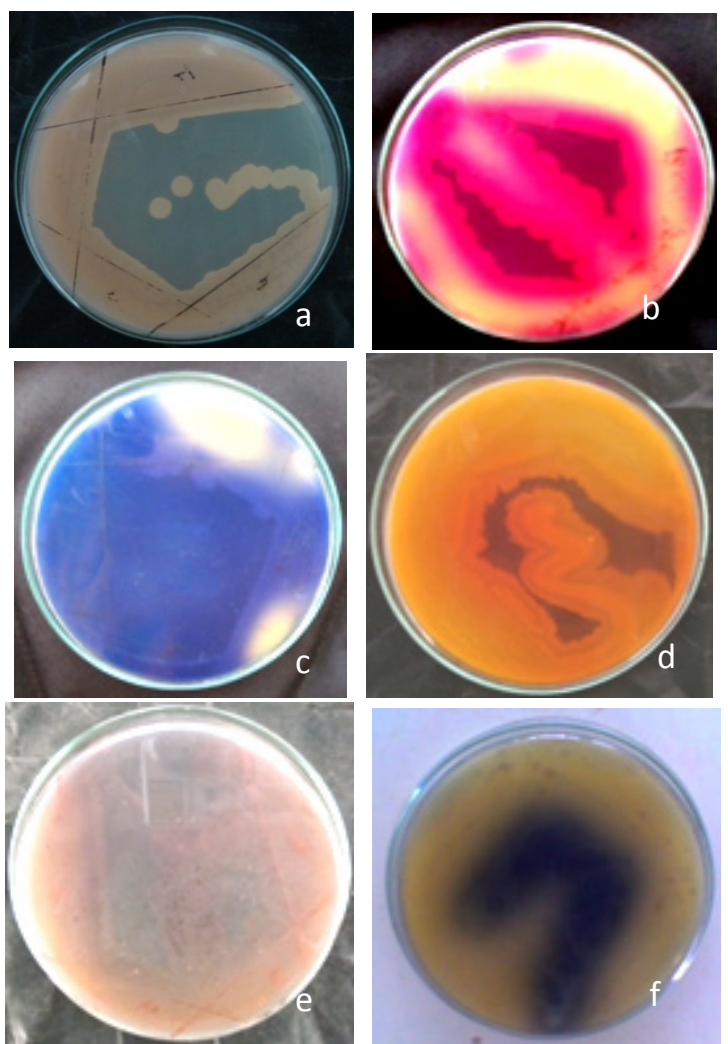

Figure 1. a. Control; b. showing degradation with Purple H3R; c. showing degradation with Red BB; d. showing degradation with Bhe 81; e. showing degradation with Dir Black; f. showing degradation with Blue 171

The requirement for yeast extract or peptone making the process economically unavailable for industrial-scale application unless alternate cheaper sources are identified $[2,21,31]$. Glucose is known to enhance the decolorization activity of biological systems $[14,32,33]$. However, there are reports that the glucose inhibits the decolorizing activ ity [34]. The variability may be due to the different microbial characteristics. Chen et a1.[2] has found that $10 \mathrm{~g} \mathrm{l}^{-1}$ concentrations of glucose led to the decolorization of RED RBN by A. hydrophila and glucose concentration of higher than $15 \mathrm{~g} \mathrm{l}^{-1}$ inhibited appreciably the azo reduction of azo dye by the same bacteria.

\subsection{Optimization of Concentration of Dye Degradation}

$\mathrm{S} 1$ isolate showed degradation of Red BB dye in varying concentration (Table 1). Out of ten different concentrations used, $0.05 \%$ concentration was degraded most efficiently within 24 hours. While $0.10 \%-0.25 \%$ concentration was degraded in 48 hours. Degradation was found after 72 hours in $0.30 \% \& 0.35 \%$ concentration. Moderate degradation was seen in $0.40 \%$ and $0.45 \%$ concentration of dye. But the degradation was very less or meagre even after 96 hours of incubation in $0.50 \%$.

All microorganisms have ability to grow on different medium. Hence, different types of media have been introduced for the growth of different types of microorganis ms. An analysis of the result obtained for the degradation of dye shows that only five different dyes were degraded. This could have been due to the fact that the microorganisms present in the isolates might have the efficiency to degrade only five dyes but not the rest (i.e. 7 dyes) used. Studies on 4-ABS degrading strains have also shown that the all different dye degrading microorganisms are highly specific, as they can utilize only 4-ABS and not other benzenesulfonates[35]. The 2-ABS degrading Alcaligenes sp. strain O-1 can utilize two other aromatic sulfonates, benzene and toluene sulfonate, for growth. However, cell extracts of this strain can desulfonate at least six substrates[36]. This suggests the presence of highly specific transport systems for the uptake of aromatic sulfonates in these cultures. Thus the isolated bacteria may still have restricted substrate specificity.

In order to test the activity for the degradation of dye, all the isolates were tested for the Red BB dye degradation. Lower the concentration higher the degradation efficiency and vice-versa pattern were obtained. The biodegradation capability of the dyes varies from organis $m$ to organism[37]. $\mathrm{He}$ found that out of 15 isolates 4 had the maximum decolorizing capability after 72 hours of incubation. The similar finding has also been reported by Chen et al.[2].

Table 1. Concentration of Red BB dye degraded by the isolate number S1

\begin{tabular}{ccccc}
\hline Incubation (hrs) & \multicolumn{5}{c}{ Concentration of dye (in \%) } \\
& 24 & 48 & 72 & 96 \\
\hline 0.05 & +++ & ++ & +++ & +++ \\
0.10 & - & ++ & +++ & +++ \\
0.15 & - & + & +++ & ++ \\
0.20 & - & + & ++ & +++ \\
0.25 & - & - & ++ & ++ \\
0.30 & - & - & + & ++ \\
0.35 & - & - & + & ++ \\
0.40 & - & - & + & + \\
0.45 & - & - & + & + \\
0.50 & - & - & + & + \\
\hline
\end{tabular}

' +++ ' - indicates very good degradation, ' + ' - indicates moderate degradation '+' - indicates less degradation and '-'- indicates no degradation.

\subsection{Bioche mical Test}

The biochemical tests for all three isolates are depicted in Table 2. Isolate $\mathrm{S} 1$ showed the positive result in indole production test, methyl red test, urease test, triple sugar iron test and sugar test. Isolate number S2 showed the positive 
result with indole production test, methyl red test, urease test, ammonia, triple sugar iron test and sugar test. Isolate no S3 showed the positive with indole production test, methyl red test, urease test, triple sugar iron test and sugar test.

Table 2. Biochemical tests for all three isolates

\begin{tabular}{|c|c|c|c|c|}
\hline \multirow{2}{*}{ Tests } & & \multicolumn{3}{|c|}{ Isolates } \\
\hline & & $\mathrm{S} 1$ & $\mathrm{~S} 2$ & S3 \\
\hline \multicolumn{2}{|l|}{ Methyl Red test } & + & + & + \\
\hline \multicolumn{2}{|l|}{ Indole production test } & + & + & + \\
\hline \multicolumn{2}{|l|}{ Voges Proskauertest } & - & - & - \\
\hline \multicolumn{2}{|l|}{ Nitrate Reduction test } & - & - & - \\
\hline \multicolumn{2}{|l|}{ Ammonia reduction test } & - & - & - \\
\hline \multicolumn{2}{|l|}{ Phenylalanine deaminaion test } & - & - & - \\
\hline $\mathrm{H}_{2} \mathrm{~S}$ production test & & - & - & - \\
\hline \multicolumn{2}{|l|}{ Simmon's Citrate test } & - & - & - \\
\hline \multicolumn{2}{|l|}{ Catalase test } & - & - & - \\
\hline \multicolumn{2}{|l|}{ Gelatine test } & - & - & + \\
\hline \multirow{2}{*}{ Oxidation Fer- mentation test } & Oxi & $\mathrm{A} \& \mathrm{G}$ & - & $\mathrm{A} \& \mathrm{G}$ \\
\hline & Fer & $\mathrm{A} \& \mathrm{G}$ & - & $\mathrm{A} \& \mathrm{G}$ \\
\hline \multicolumn{2}{|l|}{ Ureatest } & + & + & + \\
\hline \multirow{4}{*}{ Triple sugar iron test } & A & + & + & + \\
\hline & G & - & - & - \\
\hline & $\mathrm{H}$ & - & - & - \\
\hline & $\mathrm{Al}$ & + & + & + \\
\hline \multicolumn{2}{|l|}{ Starch hydrolysis test } & - & + & - \\
\hline \multirow{2}{*}{\multicolumn{2}{|c|}{$\begin{array}{l}\text { Casein hydrolysis test } \\
\text { Dehydrogenase test }\end{array}$}} & - & - & - \\
\hline & & - & - & - \\
\hline \multirow{4}{*}{ Sugar test } & $\mathrm{Gl}$ & + & $\perp$ & + \\
\hline & $\mathrm{Mn}$ & + & - & + \\
\hline & $\mathrm{L}$ & + & - & - \\
\hline & $\mathrm{S}$ & + & - & + \\
\hline
\end{tabular}

'++'- indicates good result, '+' - indicates average result '-'- indicates negative result, ' $\perp$ '- indicates half positive result. A denotes for acid, Al for alkaline, $\mathrm{G}$ for gas and $\mathrm{H}$ for $\mathrm{H}_{2} \mathrm{~S}$ production. Gl-glucose, $\mathrm{S}$ - sucrose, Mn- mannitol, L- lactose, No ' 1 -3' indicates the number of isolates.

The result of biochemical tests (Table 3) for all three isolates reveals that isolate $\mathrm{S} 1$ can produce the enzyme tryptophanase and indole production, citrate permease (citrate as carbon and energy source), catalase enzyme, degradation of glucose oxidatively as well as fermentatively, production of acid and gas (ferment lactose and/or sucrose and fermentation of sugar glucose, sucrose and mannitol). Isolate S2 showed presences of enzyme enzyme tryptophanase and indole production and urease. Whereas Is olate $\mathrm{S} 3$ showed the pres ence of en zy me tryptophanase and indole production, gelatinase, degradation of glucose oxidatively as well as fermentatively, production of acid and gas (allow to ferment lactose and/or sucrose) and fermentation of sugar lactose, sucrose, mannitol and glucose. All together is olate S1 showed positive tests for all the sugar used. Biochemical tests have been done by several workers [38] on bacterial co mmun ities.

\subsection{Cellular Fatty Acid Profiling}

The result of cellular fatty acid profiling for the partial identification of the isolate S1 was done using Gas Chromatographic technique and the graph is shown as table 3 and figure 7 .

On the bas is of the data obtained the RTSBA66.00 library was used to match the probable name of the isolate. A close look to the graph and data revealed that the is olates shoed the 0.825 similarity with Bacillus cereus GC subgroup A, 0.552 with $B$. thuringiensis sub sp. israelensis and 0.511 with $B$. thuringiensis sub sp. Kurstakii.

Total cellular fatty acids profiling is a reliable tool for identification of microorganisms. A close look to the similarity index revealed that isolate number $\mathrm{S} 1$ belongs to the $B$. cereus GC subgroup A (similarity index 0.825 ) in comparison to the rest $(0.552$ for $B$. thuringiensis sub sp. israelensis and 0.511 for $B$. thuringiensis sub sp. Kurstakii). Identification of several microorganisms (Pseudomonas cepacia, Candida dubliniensis, C. albicans, Prevotella intermedia, P. nigrescens, Aeromonads, B. Mycoides, Acidovorax avenae subsp. citrulli, Xanthomonas, Stenotrophomonas maltophilia etc.) have been done by cellu lar fatty acid profiling by the several workers of various fields like marine science[39,40], medical research[41,42], dental research[43] taxonomy[44], soil science[45], plant pathology $[46,47]$, entomology [48] etc.

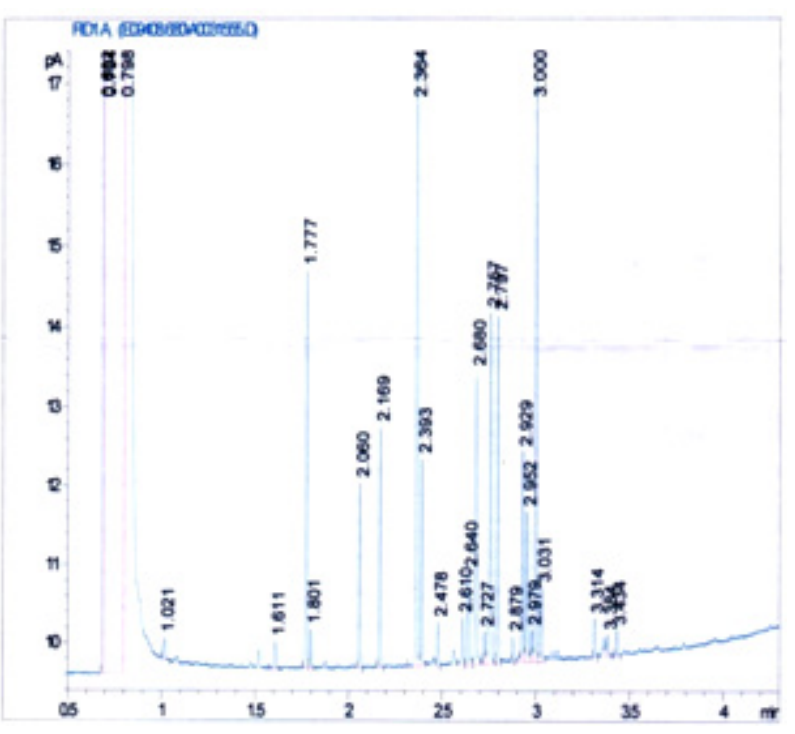

Figure 2. GC graph showing the total cellular fatty acid profiling

\section{Conclusions}

The textile, dyeing and finishing industry use wide variety of dyestuffs due to the rapid changes in the customer's demands. Thus by the use of the above isolates sustainable biodegradation of the harmful azo dyes utilized by the dye, textile, paper ink etc. industries can be possible. These methods are not only eco-friendly but also commercially viable even for the small scale industries. A thorough investigation, taking into consideration of certain parameters such as optimization of the dye concentration for the isolates as well as for the dye to be degraded, effect of physicochemical parameters on degradation etc. at large scale is necessary to provide unequivocal evidence for the usefulness of these isolates in sustaining dye degradation capability. 
Table 3. Total cellular fatty acid profiling using Gas Chromatography

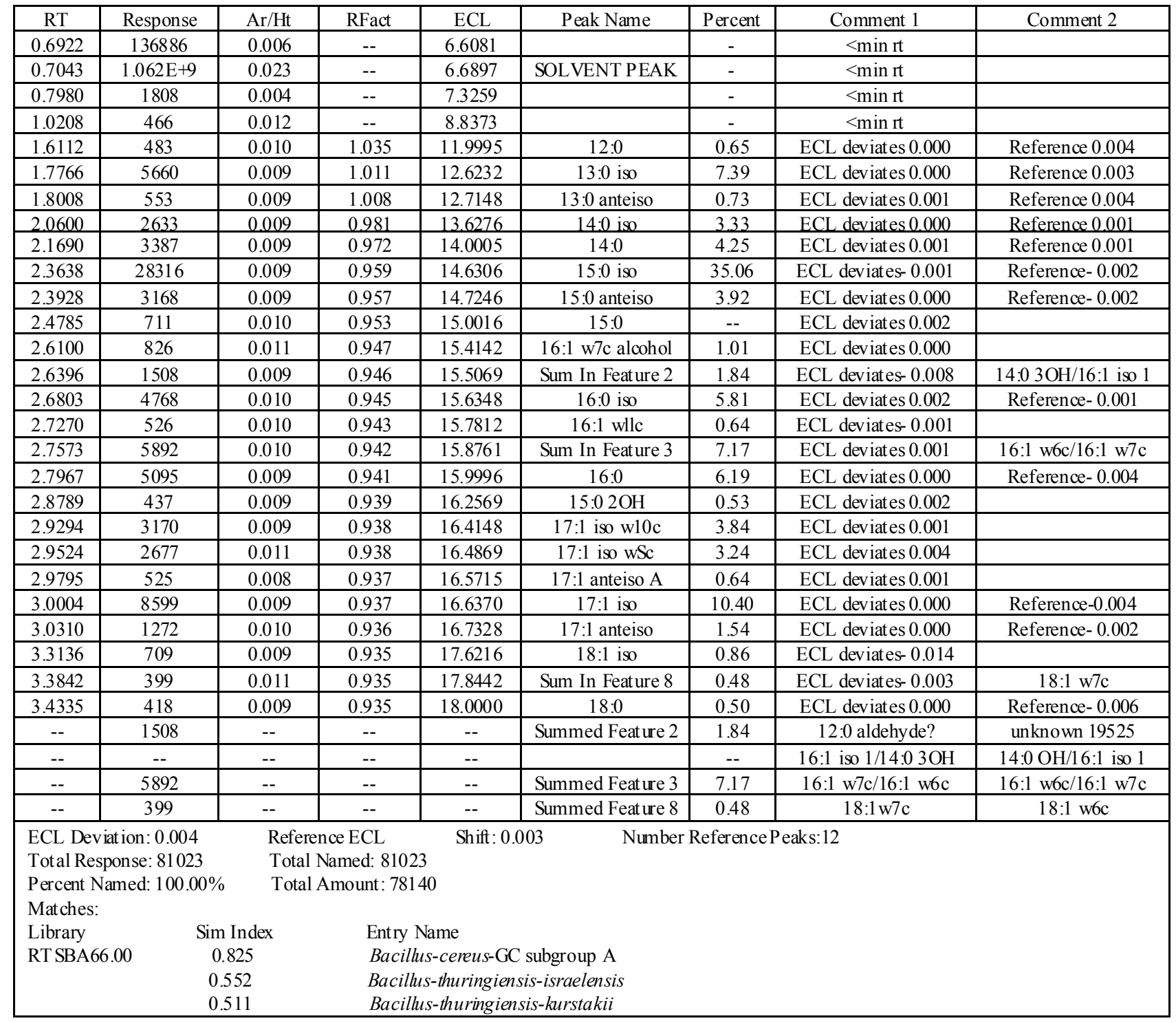

\section{ACKNOWLEDGMENTS}

We thank Charutar Vidya Mandal, New Vallabh Vidyanagar for providing facility and financial support to undertake the research work.

\section{REFERENCES}

[1] N. C. Tan, A. Borger, P. Slender, A. V. Svitelskaya, G Lettinga and J. A. Field, Degradation of azo dye Mordant Yellow 10 in a sequential anaerobic and bioaugmented aerobic bioreactor. Water Sci. Tech., vol. 42, no.5-6, pp. $337-344,2000$.

[2] K. C. Chen, J. Y. Wu, D. J. Liou and S. J. Hwang, Decolorization of textile dyes by newly isolated bacterial strains. J Biotech., vol. 101, pp.57-68, 2003.

[3] C. M. Carliell, S. J. Barclay, C. Shaw, A. D. Wheatley and C.
A. Buckley, The effect of salts used in textile dyeing on microbial decolourisation of a reactive azo dye. Environ. Tech., vol. 19, no.11, 1133-1137, 1998.

[4] G. M. Shaul, , T. J. Holdsworth, , C. R. Dempsey and K. A. Dostal, Fate of water-soluble azo dyes in the activated sludge process. Chemosphere, vol. 22, pp. 107-119, 1991.

[5] Y.M.Slokar and A. M. Le Marechal, Methods of decoloration of textile wastewater. Dyes Pigm, vol. 37, no. 4, pp. 335-356, 1998.

[6] A. F. Strickland and W. S. Perkins, Decolorization of continuous dyeing wastewater by ozonation. Text. Chem. Color., vol. 27, no. 5, pp.11-15, 1995.

[7] K. T. Chung and C. E. Cerniglia, Mutagenicity of azo dyes: structure-activity, Mutat. Res., vol. 277, pp. 201-220, 1992.

[8] V. S. Houk, The genotoxicity of industrial wastes and effluents - a review. Mutat. Res., vol. 277, pp. 91-138, 1992.

[9] P. Rajaguru, L. Vidya, B. Baskarasethupathi, P.A. Kumar, M. Palanivel and K. Kalaiselvi, Genotoxicity evaluation of 
polluted ground water in human peripheral blood ly mphocytes using the comet assay. Mutat. Res., vol. 517, pp. 29-37, 2002.

[10] G. A. Umbuzeiro, H. Freeman, S. H. Warren, D. P. Oliveira, Y. Terao, T. Watanabe and L. D. Claxton, The contribution of azo dyes to the mutagenic activity of the Cristais River. Chemosphere, vol. 60, pp. 55-64, 2005.

[11] T. H. Kim, Y. Lee, J. Yang, B. Lee, C. Park and S. Kim, Decolorization of dye solutions by a membrane bioreactor (MBR) using white-rot fungi. Desalination, vol. 168, pp. 287-293, 2004.

[12] N. P. Tantak, and S. Chaudhari, Degradation of azo dyes by sequential Fenton's oxidation and aerobic biological treatment. J Hazard. Mat., vol. B136, pp. 698-705, 2006.

[13] E. Forgas, T. Cserhati, and G. Oros, Removal of synthetic dyes wastewaters: a review. Environ. Int., vol. 30, pp. 953-971, 2004

[14] I. K. Kapdan, and F. Kargi, Biological decolorization of textile dy estuff containing wastewater by Coriolus versicolor in a rotating biological contractor. Enz. Microb. Tech., vol. 30, pp. 195-199, 2002.

[15] S. Sandhaya, S. Padmavathy, K. Swaminathan, Y. V. Subrahmanyam and S. N. Kaul, Microaerophilic-aerobic sequential batch reactor for treatment of azo dyes containing simulated wastewater. Process Biochem., vol. 40, pp. 885-890.

[16] K. Ali, M. A. Javid and M. Javid, Pollution and industrial waste. $6^{\text {th }}$ National Congress Soil Science, Lahore, pp. 122-131, 1996

[17] G. McMullan, C. Meehan, A. Conneely, N. Nirby, T. Robinson, P. Nigam, I. M. Banat, R. Marchant and W. F. Smyth, Mini review: microbial decolourisation and degradation of textile dyes. Appl. Microbiol. Biotech., vol. 56, pp. 81-87, 2001 .

[18] Z. Zheng, R. E. Levin, J. L. Pinkham and K. Shetty, Decolorization of polymeric dyes by a novel Penicillium isolate. Proc. Biochem., vol. 34, pp. 31-7, 1999.

[19] W. Zhou and W. Zimmermann, Decolorization of industrial effluents containing reactive dyes by actinomycetes. FEMS Microbiol. Lett., vol. 107, pp. 157-162, 1993.

[20] F. B. Dilek, H. M. Taplamacioglu, E. Tarlan, Colour and AOX removal from pulping effluents by algae. Appl. Microbiol. Biotechnol., vol. 52, pp. 585-591, 1999.

[21] P. Nigam, I. M. Banat, D. Singh and R. Marchant, Microbial process for the decolorization of textile ef.uent containing azo, diazo and reactive dyes. Proc. Biochem., vol. 31, no. 5, pp. 435-442, 1996.

[22] D. K. Sharma, H. S. Saini, M. Singh, S. S. Chimni and B. S. Chadha Isolation and characterization of microorganisms capable of decolorizing various triphenylmethane dyes. J. Basic Microbiol., vol. 44, no. 1, pp. 59-65, 2004.

[23] P. B. David and D. A. Steven, Mechanism White Rot Fungi use to degrade pollutants. Environ. Sci. Tech., pp. 78-87, 1994.

[24] I. M. Banat, P. Nigam, D. Singh, R. Marchant, Microbial decolorization of textile dye-containing effluents: a review. Biores. Tech., vol. 58, pp. 217-227, 1996.

[25] R. Patel, Experimental Microbiology, Aditya Press, Ahmedabad, 2008.

[26] L. P. David, F. R. Harden Jr., K. E. Kearns and M. V. Zombeck,1996, The ROSAT High Resolution Imager (HRI), USRSDC/SAO Calibration Report 1996 February, revised, U.S. ROSAT Science Data Center, SAO, Cambridge, MA, the revised version is available under ftp://legacy.gsfc.nasa.g ov/rosat/doc/hri/hri_report/

[27] H. C. Sharma and C. Lai, Sugar Mill Effluent Quality and Suitability for Irrigation. Agron 98: International Symposium. UA Faisalabad, Pakistan, 1998.

[28] R. A. Sial, M. F. Chaudhary, S. T. Abbas, M. I. Latif and A. G. Khan, Quality of effluents from Hattar Industrial Estate. $J$ Zhejiang Univ. SCIENCE B, vol. 7, no. 12, pp. 974-980, 2006.

[29] A. J. Robson and C. Neal Regional water quality of the River Tweed. Sci. Total Environ., vol. 194-195, pp. 173-192, 1997.

[30] A. Pandey P. Singh and L. Iyengar, Bacterial decolorisation and degradation of azo dyes. Int. Biodeter. Biodegrad., vol. 59, pp. 73-84, 2007.

[31] S. Moosvi, H. Keharia and D. Madamwar, Decolourization of textile dye reactive 5 by a newly isolated bacterial consortium RUM II.I. World. J Microbiol. Biotechnol. vol. 21, pp. 667-672, 2005.

[32] W. Haug, A. Schmidt, B. No“rtemann, D. C. Hempel, A. Stolz and H. J. Knackmuss, Mineralization of the sulfonated azo dye mordant yellow 3 by a 6 -aminophthalene-2- sulfonated degrading bacterial consortium. Appl. Environ. Microbiol., vol. 57, pp. 3144-3149, 1991.

[33] C. M. Carliell, S. J. Barclay, N. Naidoo, C. A. Buckley, D. A. Mulholland and E. Senior, Anaerobic decolorisation of reactive dyes in conventional sewage treatment processes. Water SA, pp.341-344, 1994.

[34] J.S. Knapp and P. S. Newby, The microbial decolourisation of an industrial effluent containing a diazo-linked chromophore. Water Res., vol. 29, pp. 1807-1809, 1995.

[35] P. Singh, N. K. Birkeland, L. Iyengar, and R. Gurunath, Mineralization of 4-aminobenzenesulfonate (4-ABS) by Agrobacterium sp. Strain PNS-1. Biodegrad., 1572-9729, 2006.

[36] T. Thurnheer, T. Kohler, A.M. Cook and T. Leisinger, Orthanilic acid and analogues as carbon sources for bacteria: growth physiology and enzymic desulphonation. J Gen. Microbiol., vol. 132, pp. 1215-1220, 1986.

[37] B. Barraga'n, C. Costa and C. Ma'rquez, Biodegradation of azo dy es by bacteria on solid media. Dyes and pigments, vol. 75 , pp. 73-81, 2007

[38] X. Modamio and S. Mallo, Heavy metals effect on bacterial communities from coastal sediments. Acte Coll. GERBAM, Brest 1-5 October 3: pp. 597-600, 1984.

[39] G. M. Mukwaya and D. F. Welch, Subgrouping ofPsedomonas cepacia by cellular fatty acid composition. $J$ Clin. Microbiol., vol. 27, pp. 2640-2646, 1989. 
[40] H. Peltroche-Llacsahuanga, S. Schmidt, M. Seibold, R. Lütticken and G. Haase, Differentiation between Candida dubliniensis and Candida albicans by fatty acid methyl ester analysis using gas-liquid chromatography. J Clin. Microbiol., vol. 38, pp. 3696-3704, 2000.

[41] G. J. Osterhout, V. H. Shull and J. D. Dick, Identification of clinical isolates of gram-negative nonfermentative bacteria by an automated cellular fatty acid identification system. $J$ Clinical. Microbiol., vol. 29, pp. 1822-1830, 1991.

[42] M. J. Hopkins, R. Sharp and G. T. Macfarlane, Age and disease related changes in intestinal bacterial populations assessed by cell culture, 16S rRNA abundance, and community cellular fatty acid profiles. Gul., vol. 48, pp. 198-205, 2001.

[43] G. J. Debelian, I. Olsen and L. Tronstad,. Anaerobic bacteremia and fungemia in patients undergoing endodontic therapy: an overview. Ann. Periodontol. vol. 3, pp. 281-287, 1998.

[44] G. Huys, P. Kämpfer, M. Vancanneyt, R. Coopman, P. Janssen and K. Kersters, Effect of the growth medium on the cellu lar fatty acid composition of aeromonads: consequences for the chemotaxonomic differentiation of DNA hybridization groups in the genus Aeromonas. J Microbiol. Methods, vol. 28, pp. 89-97, 1997.

[45] F. Von Wintzingerode, F. A. Rainey, R. M. Kroppenstedt and E. Stackebrandt Identification of environmental strains of Bacillus mycoides by fatty acid analysis and species-specific 16S rDNA oligonucleotide probe. FEMS Microbiol. Ecol., vol. 24, pp. 201-209, 1997.

[46] D. J. Norman, A. R. Chase, N. C. Hodge and R. E. Stall, Differentiation of three species of Xanthomonas and Stenotrophomonas maltophilia using cellular fatty acid analy sis. Eur. J Plant Pathol., vol. 103, pp. 687-693, 1997.

[47] R. R. Walcott, D. B Langston Jr., F. H. Sanders Jr. and R. D. Gitaitis, Investigating intraspecific variation of Acidovorax avenae subsp. citrulli using DNA fingerprinting and whole cell fatty acid analysis. Phytopathol., vol. 90, pp. 191-196, 2000 .

[48] J. P. Siegel, A. R. Smith and R. J. Novak, Cellular fatty acid analysis of isolates of Bacillus thuringiensis serovar kurstaki, strain HD-1. Biol Control, vol. 17, pp. 82-91, 2000. 